\title{
Erratum
}

\section{Ferromagnetic oxide heterostructures on silicon - ERRATUM}

Srinivasa Rao Singamaneni, J. T. Prater, Fan Wu, and J. Narayan

doi: 10.1557/mrc.2016.22, Published by Materials Research Society with Cambridge University Press, 19 July 2016.

Singamaneni et al. ${ }^{1}$ was listed as a Research Letter. It was meant to be an Invited Research Letter for the special issue on Functional Oxides.

The authors and editors regret this oversight, and the original has since been corrected.

\section{Reference}

1. S.R. Singamaneni, J.T. Prater, F. Wu, and J. Narayan: Ferromagnetic oxide heterostructures on silicon. MRS Communications 6(3), (2016). doi: 10.1557/ mrc.2016.22. 